\title{
Analysis of Materials and Processes Affecting SMT Printing Quality
}

\author{
Xiaoming Hu \\ Dept. Electronic \& Electrical Engineering, Wuhan Railway Vocational College of Technology, Wuhan, China \\ Wuhan Jiangxia District Hidden Dragon Road, No. 1,430205 \\ Email: huxiaolili@tom.com
}

Keywords: material and processes, stencil and printer, affect SMT printing quality.

\begin{abstract}
This paper introduces the key problems affacting SMT printing quality. It relates the materials and processes, such as, stencil designing and manufacturing, aperture size, etc. The paper discusses the solder paste and the printer, which can affect the quality of printing. Automatic printers can be programmed for sueegee travel speed, squeegee pressure, and the frequency of cleaning the underside of stencil, and the vision system are key factors affecting the quality of SMT printing.
\end{abstract}

Because Surface Mount components are small and can be mounted on either side of the board, SMT have achieved widespread usage. The first important process is printing in SMT, in the paper we want to analysis some key Materials and Processes Affecting SMT Printing Quality.

\section{Stencil}

Stencils are used to print solder paste on the PCBs. They are often made of Stainless Steel or Nickel and are manufactured by different processes described below.

\subsection{Stencil design}

Due to the need for fine pitch components, as the size of the aperture (opening in the stencil) becomes smaller and smaller, they become "tall-narrow" apertures. In such cases, the apertures may be filled with solder paste but not completely released, or sometimes not even completely filled and hence get no deposits. In order to solves this problem, aperture walls are made as smooth as possible. Also, molecular layer nano coatings are put on the stencil walls so that the solder paste does not stick. Consistent fill and release is the most important output of stencil printing. When the stencil is down on the board, paste is filling the aperture and it's in contact with the pad and walls of the stencil. The contact is judged by taking the ratio of these areas i.e. the ratio of the area of the pad to the area of the walls. This is called Area Ratio. In general including stencils with tall and narrow apertures, an area ratio greater than 0.66 is recommended.

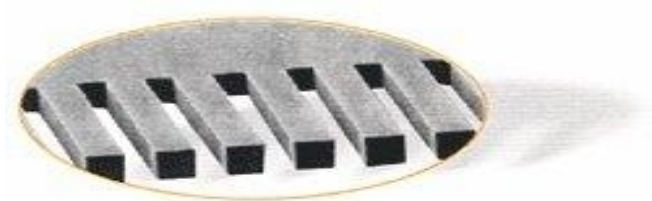

Fig.1 SMT stencil of electroformed ${ }^{[1]}$

If apertures length is L, width is $\mathrm{W}$, and high is $\mathrm{T}$. we have an experienced formula:

Stencil aspect (width and high) ratio formula: 


$$
\frac{W}{T}>1.5
$$

Stencil area ratio formula:

$$
\frac{W \times L}{2 T(W+T)}>0.66
$$

\subsection{Manufacturing methods}

\subsubsection{Laser cutting}

The use of laser technology allows having tighter tolerances and greater accuracy. The aperture walls can be smoothed through electro-polishing and/or nickel plating. The laser cutting process results in trapezoidal apertures that can create better solder paste release characteristics.

The repeatability of dimensions in laser-cut stencils is generally better than that of chemical etching. With laser cutting, there are no photo films requiring precise alignment.

\subsubsection{E-FAB stencil}

This stencil is formed by the process of electroforming nickel. Hence the name E-FAB. The nickel has better wear characteristics than steel and electroforming creates smooth tapered aperture walls. The process also creates a ridge along the bottom of the stencil that can improve stencil-to-board gasketing and result in more consistent solder paste release. ${ }^{[2]}$

\subsubsection{Chemical etching (or Deposition)}

The main deposition method used with stencil lithography is physical vapor deposition. This includes thermal and electron beam physical vapor deposition, molecular beam epitaxy, sputtering, and pulsed laser deposition. The more directional the material flux is, the more accurate the pattern is transferred from the stencil to the substrate. ${ }^{[3]}$

\subsection{Stencil Selection and Application}

\subsubsection{Stencil selection}

In order get good printing quality, we should use the stencil right. For fine pitch stencils $(<20$ mils pitch, 10 mils aperture), even with a 5 mils stencil which is the most commonly used stencil thickness, the area ratio is below 1.5. This necessitates the use of a thinner stencil. For BGA/CSP and other very small Apertures, the Area Ratio is used. It should be greater than 0.66 , as this ensures a high probability of good fill and release. An area ratio below 0.66 would mean a much less reliable process.

Illustrations of the various dimensions in the table below (unit:mil)

$\begin{array}{lllll}\text { Pitch } & \text { Pad Width } & \text { Aperture } & \text { Stencil Thickness } & \text { Aspect Ratio } \\ 25 & 15 & 12 & 6 & 2.0 \\ 20 & 12 & 9-10 & 5-6 & 1.7 \\ 15 & 10 & 7-8 & 5 & 1.4 \\ 12 & 8 & 5-6 & 4-5 & 1.2\end{array}$

Aperture size should be smaller than the pad size to avoid the excess solder paste or production of solder balls.

Example: A 6 mils stencil is to be designed for 20 mils pitch QFPs and 60 mils BGA.(a) What is the pad and aperture width you would propose for the QFPs? What is the aspect ratio?

answer :(a) Pad Width $=12$ mils; Aperture Width $=10$ mils

(From the formula--- 1.)Aspect Ratio $=\mathrm{w} / \mathrm{t}=10 / 6=1.67$

(b) What diameter would you propose for the pads and apertures for the BGA? What is the area ratio?

answer:(b) Pad Diameter = 32 mils; Aperture Diameter = 30 mils; 
(from the formula--- 2.)Area Ratio = 30/24 = 1.25

\subsubsection{Stencil Application}

The purpose using stencil is get need varying amounts of solder paste to PCBs. we recommend step down stencils .others, Some general guidelines for stencil handling are mentioned below. (better as TPM amagment). They are particularly useful for improved life and better performance of stencils.1).Clean stencils after use, remove any solder paste on them or within the apertures.2).Store the clean stencils in a designated area. They should not be left out, as they are more likely to be damaged.3).Inspect stencils for wear or damage before using them.4).Identify stencils with job numbers. This reduce the mishandling or misplacing of stencils.

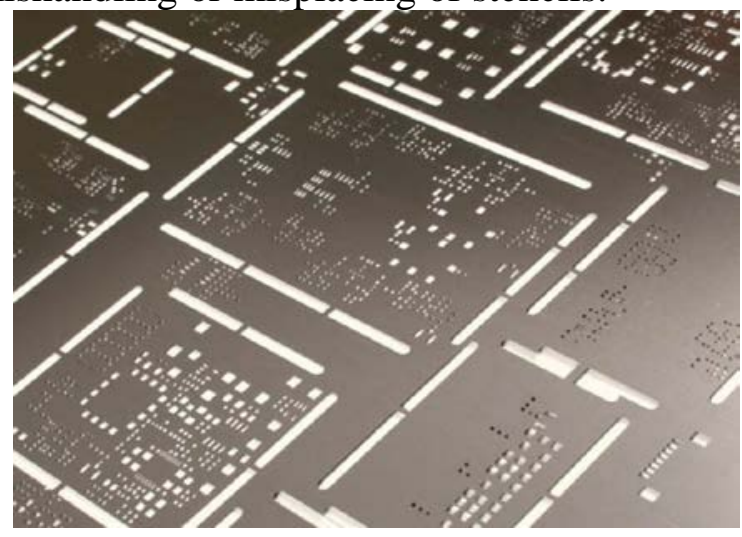

Fig.2 PCB stencil [1]

\section{Solder Paste Printing Equipment and Parameters}

Automatic stencil solder paste printing machine for PCB in SMT is important.

The solder paste stencil printers available on market today fall into two categories: laboratory and production. the only different may be in the level of automation to control printing parameters. production applications usually call for large equipment with semi-automatic or automatic control features. mainly have high printing accuracy. automatic printers can be programmed for squeegee travel speed, squeegee, amount and frequency of a constant bead of paste application, and the frequency of cleaning the underside of the stencil. They may also include automatic board loading and unloading and an optical stencil to indicate transfer of the board from printer to pick-and -place machine. A vision system may be also included to accurately match the stencil with the board.

Above we don't introduce the screen printing. the basic principle of application paste is essentially the same whether screen or stencils are used. a screen made of a woven wire mesh is stretched over a frame with a glued-on photosensitive emulsion. screen printing has been adopted for surface mounting because of its many advantages, but chiefly its lower cost. Usually screen printing requires a slower speed and the solder paste should be easy for printing.

In stencils, instead of screen mesh, the desired opening is chemically etched out in metal sheets, or cut with laser. a stencil provides $100 \%$ open area for the paste to be printed through. ${ }^{[4]}$

Table 1. .Solder printing equipment variables.

PCB :

Max PCB Size ,Min PCB Size ,PCB thickness, Max PCB Weight Printing Print head Cylinder driver, Mechanical Limit

Frame Size, Max Printing Area

Squeegee

Squeegee Type ,Squeegee Length , Squeegee Height ,Squeegee Thickness

Modes of operation

Print Mode Single or Double Squeegee Printing 


\author{
Stencil Snap-off , Print Speed \\ Print Pressure Mechanical Limit, Print Route \\ Pattern-match), Repeat Position Accuracy \\ Cycle Time ,Power Supply, Air supply \\ Operation System Windows XP \\ Image vision \\ Machine Dimensions, Weight
}

Imaging Horizon, Adjustment Range X,Y , $\theta$

Vision System Look up/down Optics Structure/CCD/Geometry

Table 2. Solder paste printing parameters ${ }^{[5]}$ (* Will vary with equipment)

\begin{tabular}{|c|c|}
\hline $\begin{array}{l}\text { Repeat Position Accur } \\
\text { acy }\end{array}$ & $\pm 0.01 \mathrm{~mm}$ \\
\hline Printing Accuracy & $\pm 0.025 \mathrm{~mm}$ (Absolute Guarantees) \\
\hline Cycle Time & $<11$ s (Excluding Printing \& Cleaning) \\
\hline Stencil Thickness & $20 \mathrm{~mm} \sim 40 \mathrm{~mm}$ \\
\hline Squeegee Speed & $10 \sim 200 \mathrm{~mm} / \mathrm{sec}$ \\
\hline Squeegee Pressure & 0 0.5MPa with adjustable pressure reducing meter valve \\
\hline Squeegee Angle & $60^{\circ}($ Standard $) / 55^{\circ} / 45^{\circ}$ \\
\hline Squeegee Type & $\begin{array}{l}\text { Steel squeegee (standard), rubber squeegee, } \\
\text { customizable other types of squeegee. }\end{array}$ \\
\hline $\begin{array}{l}\text { Stencil SeparationSpe } \\
\text { ed }\end{array}$ & $0.1 \sim 20 \mathrm{~mm} / \mathrm{sec}$ Programmable \\
\hline Cleaning Methods & $\begin{array}{l}\text { Dry-type, wet-type, vacuum-type ( Programmable combination of Cleaning } \\
\text { methods) }\end{array}$ \\
\hline Camera System & Single digital camera with upward/downward vision system \\
\hline Air Pressure & $4 \sim 6 \mathrm{Kg} / \mathrm{cm} 2$ \\
\hline Air Consumption & Approx $0.07 \mathrm{~m} 3 / \mathrm{min}$ \\
\hline
\end{tabular}

\title{
3. Solder Paste
}

A solder paste is essentially powder metal solder mixed in a thick medium called flux. Flux is added to act as a temporary adhesive, holding the components until the soldering process melts the solder and makes a stronger physical and electric connection. The paste is a gray, putty-like material. The composition of the solder paste varies, depending upon its intended use. Generally, solder pastes are made of a tin-lead alloy, with possibly a third metal alloyed, although environmental protection legislation is forcing a move to lead-free solder.

\subsection{Metal size (mesh)}

The size and shape of the metal particles in the solder paste determines how well the paste will "print". A power metal ball is spherical in shape; this helps in reducing surface oxidation and ensures good joint formation with the adjoining particles. Irregular particle sizes are not used, as they tend to clog the stencil, causing printing defects. To produce a high quality solder joint, it's very important for the spheres of metal to be very regular in size and have a low level of oxidation.

Solder pastes are classified based on the particle size by JEDEC ${ }^{[6]}$ standard J-STD 005. ${ }^{[7]}$ The table below shows the classification type of a paste compared with the mesh size and particle size. (units :mil) ${ }^{[8]}$ 


\begin{tabular}{|c|c|c|c|c|c|c|}
\hline $\begin{array}{c}\text { Type } \\
\text { designation } \\
\text { [JEDEC] }\end{array}$ & $\begin{array}{c}\text { Mesh size in } \\
\text { lines-per-inch }\end{array}$ & $\begin{array}{c}\text { Max. size } \\
\mathbf{( n o} \\
\text { larger } \\
\text { than) }\end{array}$ & $\begin{array}{c}\text { Max. size } \\
\text { (less than } \\
\mathbf{1 \%} \text { larger } \\
\text { than) }\end{array}$ & $\begin{array}{c}\text { Particle size } \\
\text { in } \boldsymbol{\mu m} \\
\mathbf{( 8 0 \% \text { min. }} \\
\text { between) }\end{array}$ & $\begin{array}{c}\text { Avg. } \\
\text { size in } \\
\boldsymbol{\mu m}\end{array}$ & $\begin{array}{c}\text { Avg. size } \\
\text { in } \boldsymbol{\mu m} \\
\mathbf{( 1 0 \%} \\
\text { max. less } \\
\text { than) }\end{array}$ \\
\hline Type 1 & & & 150 & $150-75$ & & 20 \\
\hline Type 2 & $-200 /+325$ & & 75 & $75-45$ & 60 & 20 \\
\hline Type 3 & $-325 /+500$ & & 45 & $45-25$ & 36 & 20 \\
\hline Type 4 & $-400 /+635$ & & 38 & $38-20$ & 31 & 20 \\
\hline Type 5 & $-500 /+635$ & 30 & 25 & $25-10$ & & 10 \\
\hline Type 6 & -635 & 20 & 15 & $15-5$ & & 5 \\
\hline Type 7 & & 15 & 11 & $11-2$ & & \\
\hline Type 8 & & 11 & 10 & $8-2$ & & \\
\hline
\end{tabular}

\subsection{Flux}

According to JEDEC standard J-STD-004 "Requirements for Soldering Fluxes", solder pastes are classified into three types based on the flux types:

Rosin based pastes are made of rosin, a natural extract from pine trees. These fluxes need to be cleaned after the soldering process using a solvent (potentially including chlorofluorocarbons). Rosin fluxes are no longer predominant.

Water-soluble fluxes are made up of organic materials and glycol bases. There is a wide variety of cleaning agents for these fluxes.

A no-clean flux is made with resins and various levels of solid residues. No-clean pastes save not only cleaning costs, but also capital expenditures and floor space. However, these pastes need a very clean assembly environment and may need an inert re-flow environment.

\subsection{Important properties of solder paste}

In using solder paste for circuit assemblies, one needs to test and understand the Viscosity properties of a solder paste.

Viscosity: The degree to which the material resists the tendency to flow. In this case, varying viscosities of solder paste are desired at different levels of shearing force. Such a material is called thixotropic. When solder paste is moved by the squeegee on the stencil, the physical stress applied to the paste causes the viscosity to break down, thinning the paste and helping it flow easily through the apertures on the stencil. When the stress on the paste is removed, it regains it shape, preventing it from flowing on the circuit board. The viscosity for a particular paste is available from the manufacturer's catalog; in-house testing is sometimes needed to judge the remaining usability of solder paste after a period of use.

\subsection{Lead-free solder}

On July 1, 2006 the European Union Waste Electrical and Electronic Equipment Directive (WEEE) and Restriction of Hazardous Substances Directive (RoHS) came into effect prohibiting the inclusion of significant quantities of lead in most consumer electronics produced in the EU. In the US, manufacturers may receive tax benefits by reducing the use of lead-based solder. Lead-free solders in commercial use may contain tin, copper, silver, bismuth, indium, zinc, antimony, and traces of other metals. Most lead-free replacements for conventional 63/37 Sn-Pb solder have melting points from 5 to $20^{\circ} \mathrm{C}$ higher, though there are also solders with much lower melting points.

It may be desirable to use minor modification of the solder pots (e.g. titanium liners or impellers) used in wave-soldering, to reduce maintenance cost due to increased tin-scavenging of high-tin solder. 
Lead-free solder may be less desirable for critical applications, such as aerospace and medical projects, because its properties are less thoroughly known.

Tin-Silver-Copper (Sn-Ag-Cu, or "SAC") solders are used by two-thirds of Japanese manufacturers for reflow and wave soldering, and by about $75 \%$ of companies for hand soldering. The widespread use of this popular lead-free solder alloy family is based on the reduced melting point of the Sn-Ag-Cu ternary eutectic behavior $\left(217{ }^{\circ} \mathrm{C}\right)$, The ternary eutectic behavior of $\mathrm{Sn}$-Ag-Cu and its application for electronics assembly was discovered (and patented) by a team of researchers from Ames Laboratory, Iowa State University, and from Sandia National Laboratories-Albuquerque.

Much recent research has focused on selection of 4th element additions to Sn-Ag-Cu to provide compatibility for the reduced cooling rate of solder sphere reflow for assembly of ball grid arrays(BGA), e.g., 18/64/14/4 Tin-Silver-Copper-Zinc (Sn-Ag-Cu-Zn) (melting range of $217-220^{\circ} \mathrm{C}$ ) and 18/64/16/2 Tin-Silver-Copper-Manganese (Sn-Ag-Cu-Mn) (melting range of $\left.211-215{ }^{\circ} \mathrm{C}\right)$.

Tin-based solders readily dissolve gold, forming brittle intermetallics; for $\mathrm{Sn}-\mathrm{Pb}$ alloys the critical concentration of gold to embrittle the joint is about $4 \%$. Indium-rich solders (usually indium-lead) are more suitable for soldering thicker gold layer as the dissolution rate of gold in indium is much slower. Tin-rich solders also readily dissolve silver; for soldering silver metallization or surfaces, alloys with addition of silvers are suitable; tin-free alloys are also a choice, though their wettability is poorer. If the soldering time is long enough to form the intermetallics, the tin surface of a joint soldered to gold is very dull. ${ }^{[9]}$

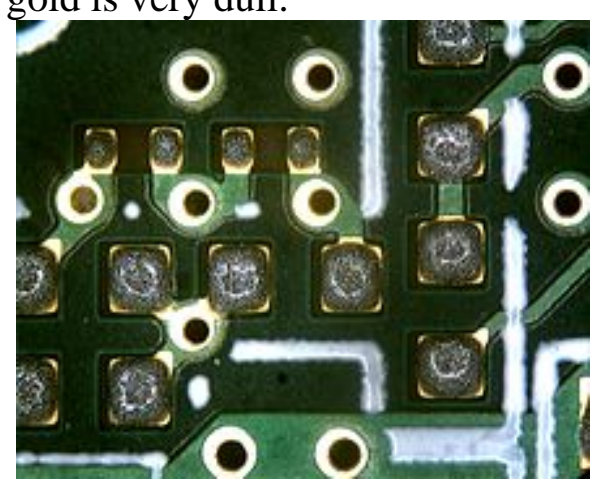

Fig.3 Solder paste printed on a PCB

\subsection{Storage}

Solder paste must be transported while refrigerated and stored in an airtight container at a temperature between $0-10{ }^{\circ} \mathrm{C}$. It should be warmed to room temperature for use.

Recently, new solder pastes have been introduced that remain stable at $26.5{ }^{\circ} \mathrm{C}$ for one year and at $40{ }^{\circ} \mathrm{C}$ for one month. ${ }^{[10]}$

Exposure of the solder particles, in their raw powder form, to air causes them to oxidize, so exposure should be minimized.

\section{Conclusion}

The key technologies affecting SMT printing quality have stencil, printing equipment, solder paste, etc. Besides, also have loading and locating board, vision alignment, Z-tower up and down, slow snap off, and unloading board.

\section{References}

[1] ---https//www.Baidu, "stencil picture."

[2] Xiaoming $\mathrm{Hu}(2016)$,"Production technology and application of thin film materials in micro fabrication". Page190-197, AMITP2016-DEStech Publications,Inc. 
[3] J. L. Wasserman; et al. (2008). "Fabrication of One-Dimensional Programmable-Height Nanostructures via Dynamic Stencil Deposition". Review of Scientific Instruments. 79: 073909. arXiv:0802.1848. Bibcode:2008RScI...79g3909W. doi:10.1063/1.2960573.

[4] --Prasad,, <surface Mount Technology-Principle and Practice.> Page 129-130, ISBN978-7-03-031487-7.

[5] https//www.baidu.high accuracy/html.

[6] JEDEC Solid State Technology Association (formerly the Joint Electron Devices Engineering Council)

[7] Solder Paste Task Group (January 1995). "J-STD-005 Requirements for Soldering Pastes". Arlington, Virginia: Electronic Industries Alliance and IPC.

[8] Tarr, Martin. "Solder paste basics". Online postgraduate courses for the electronics industry. University of Bolton. Retrieved 2010-10-03.

[9] Howard H. Manko (2001). Solders and soldering: materials, design, production, and analysis for reliable bonding. McGraw-Hill Professional. p. 164. ISBN 0-07-134417-9.

[10] Wilding, Ian (8 February 2016). "First-Ever Temperature Stable Solder Paste Unveiled" (PDF). Henkel Electronics. The Electronics Group of Henkel. Retrieved 8 February 2016. 